subjects who have negative Mantoux responses. In comparing tests it is essential to consider the positive reactors as a separate group. If this is not done a large difference in positive responses can be masked, especially if a higher proportion of the subjects are tuberculin negative

Our results have shown a greater disagreement than previous studies, although these have generally shown a tendency for the tine test to produce fewer positive responses than the Mantoux or Heaf tests. ${ }^{2-5}$ Expressed in terms of people whose test responses were read by one pair of readers, $120\left(67.8^{\circ} \%\right)$ of the 177 subjects positive on the Mantoux test had negative tine responses, but there were only two $(3.4 \%)$ with negative Mantoux results among the 59 subjects with positive tine results. The very pronounced disagreement in positive responses in our study compared with that in earlier reports raises the possibility that the tine discs we used were not giving results similar to those of the discs used in previous studies. It should be emphasised that we took particular care to follow the manufacturer's instructions for applying the test.

The general advantages claimed for the tine disc method of tuberculin testing have not been confirmed. Although the disc is technically simple to apply, table III shows that in this series there was a significant difference in the number of tine reactions over $2 \mathrm{~mm}$ between the two testers, both of whom were experienced in the use of the method. It is unlikely that nonmedical personnel would obtain consistent responses. The speed with which the test can be applied is offset by the need to confirm by further Mantoux testing a high percentage of tine readings.

Our results indicate that the tine method for selecting tuberculin-negative subjects for BCG vaccination will result in many $(67.8 \%$ ) Mantoux-positive subjects receiving BCG. This probably accounts for the high number of accelerated reactions observed when subjects have been selected for BCG vaccination by the tine method. It is also a matter of concern that in hospital staff exposed to open cases of tuberculosis the low rate of tuberculin-positive selection by the tine test may result in missed tuberculin conversion. A feature of the present study has been the high proportion (over half) of people with negative tine responses among those with considerable responses $(\geqslant 10 \mathrm{~mm})$ on the Mantoux test (table I). This leads to the possibility of failure to diagnose active tuberculosis by missing strong tuberculin reactors in any population in which the tine method is used-for example, among those served by the Schools Medical Service.

Our results indicate that the tine disc tuberculin test cannot be regarded as satisfactory for epidemiological use and little confidence can be placed in negative readings. Because of this the test cannot be recommended for clinical use. The probability of missing active tuberculosis in children and of failing to detect tuberculin conversion in exposed adults is a factor that renders the test additionally unsuitable.

The committee would like to thank Mrs L Segar for typing the text, Mrs J Rogers for typing the tables, and the Morriston Davies Trust for financial support.

Requests for reprints should be addressed to Dr J A Lunn.

\section{References}

1 National Tuberculosis and Respiratory Diseases Association, Diagnostic Standards and Classification of Tuberculosis, 12th edn. New York, National Tuberculosis Association, 1969.

${ }^{2}$ Rosenthal, S R, fournal of the American Medical Association, 1961, 177, 452.

${ }^{3}$ Rosenthal, S R, et al, fournal of the Southern Medical Association, 1967, 60, 1336.

4 Crimm, P D, fournal of the Indiana State Medical Association, 1963, 56, 422.

5 Emerson, P A, and Shaw, E M, Tubercle, 1964, 45, 36.

(Accepted 3 April 1978)

\title{
Evidence for intestinal origin of transcobalamin II during vitamin $B_{12}$ absorption
}

\author{
I CHANARIN, M MUIR, A HUGHES, A V HOFFBRAND
}

British Medical fournal, 1978, 1, 1453-1455

\section{Summary and conclusions}

The plasma binding of newly absorbed, radioactively labelled vitamin $B_{12}$ was studied during a urinary excretion (Schilling) test. Vitamin $B_{12}$, after being absorbed from the gut, enters blood attached to transcobalamin II, which seems to be derived from the ileal enterocyte. The absorbed $B_{12}$ re-enters the blood stream

\footnotetext{
Clinical Research Centre, Northwick Park Hospital, Harrow, Middlesex

I CHANARIN, MD, FRCPATH, consultant haematologist

M MUIR, FIMLS, research officer

Royal Free Hospital, Hampstead, London NW3 2QG

A HUGHES, MA, MRCP, registrar in haematology

A V HOFFBRAND, DM, FRCP, professor of haematology
}

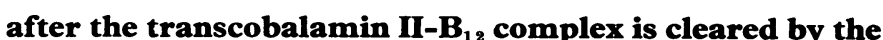
liver and it is then excreted into the urine during the Schilling test.

\section{Introduction}

It is still uncertain whether newly absorbed vitamin $B_{12}\left(B_{12}\right)$ enters portal blood in the free state and then attaches itself to plasma $B_{12}$ transport protein-transcobalamin (TC) II-as well as to other vitamin $B_{12}$ binding proteins (transcobalamins) or enters portal blood as a TC II-B ${ }_{12}$ complex. ${ }^{12}$ Further investigation of the events in the urinary excretion test for $\mathrm{B}_{12}$ absorption (Schilling test) is likely to throw light on this problem.

In this test a small dose of labelled $B_{12}$ is given by mouth and accompanied by an injection of $1000 \mu \mathrm{g}$ of unlabelled cyanocobalamin. The injected $B_{12}$ is such a large amount that all the serum $B_{12}$-binding proteins become saturated with $B_{12}$. The remaining $B_{12}$ (more than $80 \%$ of the intramuscular dose) remains unbound to protein, is filtered by the glomerulus, and excreted in the urine. Absorbed, labelled $B_{12}$ joins, directly or 
indirectly, this pool of free $B_{12}$ and some is also excreted into the urine. If $B_{12}$ enters the plasma from the gut in a free state there should be no selective attachment of this $B_{12}$ to TC II compared with the free $B_{12}$ already present in serum or to a further dose of $B_{12}$ injected intramuscularly. On the other hand, if $\mathrm{B}_{12}$ after being absorbed from the gut passes into plasma with its own supply of TC II from the intestine there will be selective binding of the orally administered $B_{12}$ to TC II compared with intramuscularly administered $\mathrm{B}_{12}$.

This study was planned to test this hypothesis by examining the transport of newly absorbed vitamin $B_{12}$ during the Schilling test.

\section{Subjects and methods}

The project was approved by the ethical committees of both the Royal Free Hospital and Northwick Park Hospital. The subjects taking part in the investigation were volunteers and agreed to participate after full explanation was given. Observations were made on five subjects all over the age of 60 and with normal intestinal function.

A baseline plasma sample was collected and an oral dose of ${ }^{57} \mathrm{Co}-\mathrm{B}_{12}$ $(0.05 \mu \mathrm{g} ; 7-9 \mu \mathrm{Ci})$ was given, followed immediately by an intramuscular injection of 700 to $800 \mu \mathrm{g} \mathrm{B}$ B $_{12}$ labelled with ${ }^{58} \mathrm{Co}-\mathrm{B}_{12}$ (3-8 $\mu \mathrm{Ci})$. The isotopes were obtained from the Radiochemical Centre, Amersham. A 24-hour urine collection was made, and blood samples were collected into a sodium-fluoride-EDTA anticoagulant $1,3,5,7$, $9,11,15$, and 24 hours after the injection.

The total ${ }^{57} \mathrm{Co}$ and ${ }^{58} \mathrm{Co}$ present in all blood samples was counted in a Wallac Autogamma counter, appropriate corrections being made for crossover. Free $B_{12}$ was removed from an aliquot of each plasma by mixing $1 \mathrm{ml}$ with the charcoal pellet from $2 \mathrm{ml}$ of albumin-coated

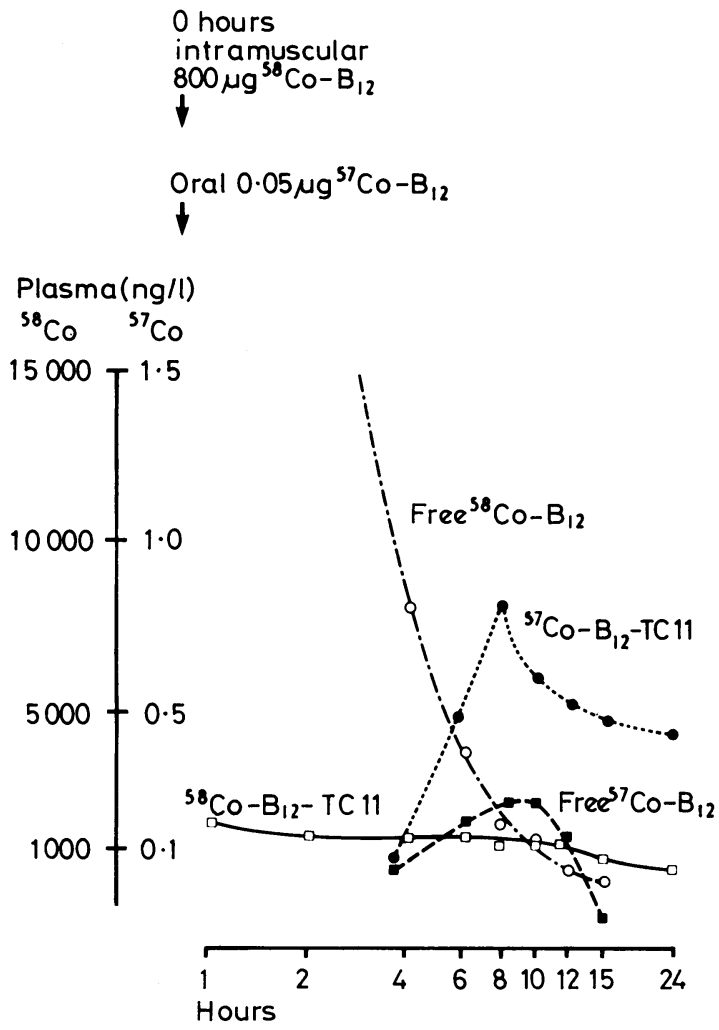

FIG 1-Plasma radioactivity after oral dose of $0.05 \mu \mathrm{g}$ of ${ }^{57} \mathrm{Co}-\mathrm{B}_{12}$ and injected dose of $800 \mu \mathrm{g}$ of ${ }^{58} \mathrm{Co}-\mathrm{B}_{12}$. Free ${ }^{58} \mathrm{Co}-\mathrm{B}_{12}$ persisted throughout the period of study and hence would have continued to saturate all available $B_{12}$ binding proteins that did not already hold $\mathrm{B}_{12 .}{ }^{57} \mathrm{Co}-\mathrm{B}_{12}$ absorbed from the gut appeared in plasma attached to TC II, whereas ${ }^{58} \mathrm{Co}-\mathrm{B}_{12}$-TC II complex remained essentially unchanged throughout this period. Presence of free ${ }^{57} \mathrm{Co}-\mathrm{B}_{12}$ was presumably due to re-entry of ${ }^{57} \mathrm{Co}-\mathrm{B}_{12}$ to plasma after uptake of $B_{12}$-TC II by tissues.

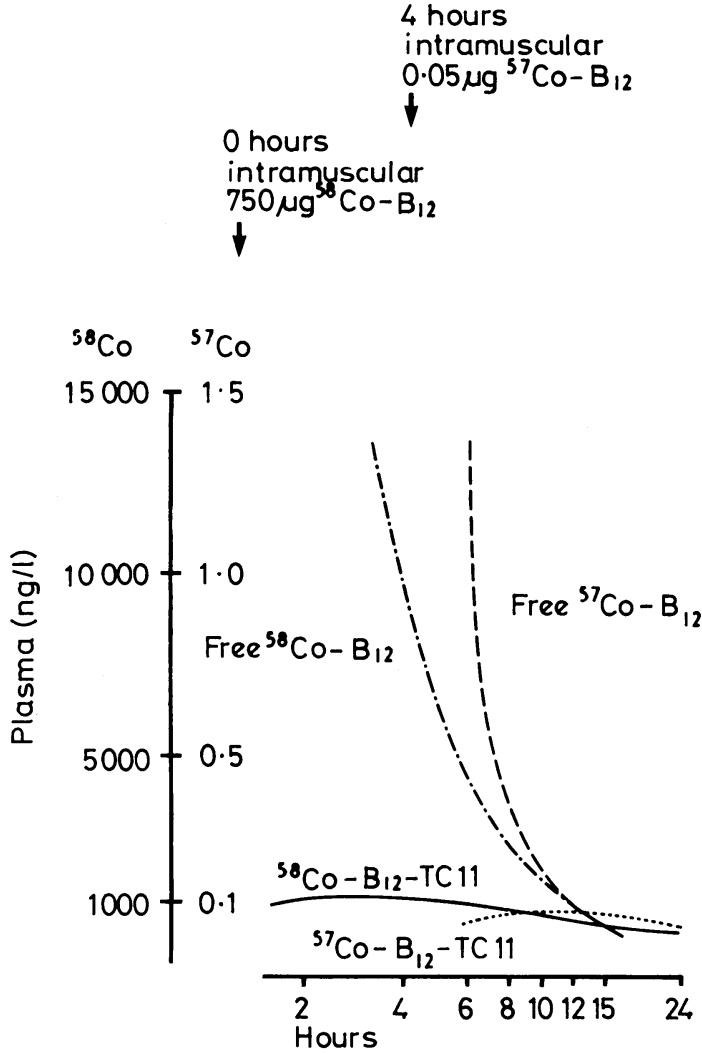

FIG 2-Plasma levels after intramuscular dose of $750 \mu \mathrm{g}$ of ${ }^{58} \mathrm{Co}-\mathrm{B}_{12}$ followed by $0.05 \mu \mathrm{g}{ }^{57} \mathrm{Co}-\mathrm{B}_{12}$ given intramuscularly four hours later. Both isotopes were largely free in plasma and largely excreted into the urine. There was no rise in ${ }^{57} \mathrm{Co}-\mathrm{B}_{12}$ - TC II as after oral dose. Thus ${ }^{57} \mathrm{Co}-\mathrm{B}_{12}$ had to pass through gut to appear in plasma as TC II complex.

charcoal (made by mixing equal volumes of albumin $10 \mathrm{~g} / 1$ distilled water with charcoal $50 \mathrm{~g} / \mathrm{l}$ distilled water), centrifuging, and recounting the supernatant.

A further aliquot of each plasma sample was dialysed against $0.04 \mathrm{M}$ phosphate buffer $\mathrm{pH} 7.35$ with $0.5 \mathrm{M} \mathrm{NaCl}$ to remove free $\mathbf{B}_{12}$. TC II-B . $_{12}$ complex and free TC II (if any) were precipitated with $50 \%$ saturated ammonium sulphate, and ${ }^{5} \mathrm{Co}$ and ${ }^{58} \mathrm{Co}-\mathrm{B}_{12}$ were counted in the precipitated material as well as in the remaining plasma, which represented $B_{12}$ largely attached to $R$ proteins (TC I and III). ${ }^{3}$

In the fifth patient the intramuscular ${ }^{58} \mathrm{Co}-\mathrm{B}_{12}$ was injected as 윽 before but the oral dose of ${ }^{57} \mathrm{Co}-\mathrm{B}_{12}$ was omitted. Instead, ${ }^{57} \mathrm{Co}-\mathrm{B}_{12} \mathrm{~N}$ equivalent to the oral dose was given intramuscularly into the opposite o buttock four hours after the intramuscular "flushing" dose. Blood $\frac{D}{O}$ and urine samples were collected and processed as described.

\section{Results}

Throughout the first 15 hours of the experiments free ${ }^{58} \mathrm{Co}-\mathrm{B}_{12}$ was $\stackrel{0}{\frac{0}{\Phi}}$ present in plasma (fig 1). There was a steady level of TC II $-{ }^{5}{ }^{8} \mathrm{Co}-\mathrm{B}_{12}$, 吕 which declined after 12 hours. ${ }^{57} \mathrm{Co}-\mathrm{B}_{12}$ entering plasma from the gut about four hours after oral administration was attached to TC II. The concentration of the complex rose until eight hours while the $\stackrel{\vec{D}}{\mathbb{D}}$ level of ${ }^{58} \mathrm{Co}-\mathrm{B}_{12}$-TC II remained constant. This TC II could not $\stackrel{\odot}{\mathcal{1}}$ have been entering the general circulation in the free state-for $\stackrel{\mathbb{Q}}{\varrho}$ exampl :, from liver-since it would have become attached to ${ }^{58} \mathrm{Co}-\mathrm{B}_{12}$, which was the predominant form of free $B_{12}$ in plasma. Essentially identical results were obtained in the four volunteers.

To test the hypothesis further, the ${ }^{57} \mathrm{Co}-\mathrm{B}_{12}$ was given by injection four hours after the flush in one subject (fig 2). In this case the ${ }^{57} \mathrm{Co}-\mathrm{B}_{12}$ as well as ${ }^{58} \mathrm{Co}-\mathrm{B}_{12}$ both disappeared steadily from plasma, $\stackrel{?}{\rightleftharpoons}$ $50 \%$ and $65 \%$ respectively being recovered from urine in the first 24 hours. There was no rise in $\mathrm{B}_{12}$-TC II activity with either isotope. Thus, passage of ${ }^{57} \mathrm{Co}-\mathrm{B}_{12}$ through the gut was necessary for the appearance of a rising ${ }^{57} \mathrm{Co}-\mathrm{B}_{12}$-TC II complex in plasma. 
The appearance of ${ }^{57} \mathrm{Co}-\mathrm{B}_{12}$-TC II complex in plasma was accompanied by the appearance of free ${ }^{57} \mathrm{Co}-\mathrm{B}_{12}$ in plasma, which reached a peak about two hours after that of ${ }^{57} \mathrm{Co}-\mathrm{B}_{12}$ TC II (fig 1). This was presumably due to exchange between free $\mathrm{B}_{12}$ and ${ }^{57} \mathrm{Co}-\mathrm{B}_{12^{-}}$TC II complex that had been cleared by the liver and other tissues with recirculation of the hitherto bound ${ }^{57}$ Co- $B_{12}$. There was also a small rise in ${ }^{57} \mathrm{Co}-\mathrm{B}_{12}$ attached to the $\mathrm{R}$ binders (TC I and III). This peaked one to two hours later than the TC II-B ${ }_{12}$, showed half the activity of free ${ }^{5} \mathrm{Co}-\mathrm{B}_{12}$, and ran parallel to it. It may have been related to the exit of ${ }^{57} \mathrm{Co}-\mathrm{B}_{12}$ from tissues.

\section{Discussion}

These studies have clarified our understanding of events in the Schilling test, which is the most widely used method of assessing $B_{12}$ absorption. They also suggest that during $B_{12}$ absorption the carrier protein, TC II, arises in the gut itself. Other workers who have tried to analyse the events in $B_{12}$ absorption in man have used an oral dose of $B_{12}$ alone and followed its attachment to plasma binders. Hall ${ }^{1}$ found that $95^{\circ}$, of absorbed $\mathrm{B}_{12}$ was attached to TC II, although in this case very little free non-TC II binder was available. England $e t \mathrm{al}^{2}$ found that the absorbed $B_{12}$ was attached to all three plasma $B_{12}$ binders. The attachment to the $R$ binders may have arisen because of recirculation of the absorbed $\mathrm{B}_{12}$ once the TC II- $\mathrm{B}_{12}$ complex had reached the liver.
The more elaborate approach we used seems to provide a more decisive answer because the flushing dose, by saturating all the serum $B_{12}$ binders and leaving an excess of free circulating $B_{12}$, makes the free binders circulating before the saturating dose ineligible to participate in transport of the newly absorbed $B_{12}$.

It would seem that the absorbed $B_{12}$ during the Schilling test enters plasma only as a $B_{12}$-TC II complex. This has a half life of about five minutes in plasma, ${ }^{4}$ since it is rapidly removed by the liver and possibly by other organs. The $B_{12}$ newly deposited in the liver and other tissues may then exchange with $B_{12}$ from the flushing dose. The exchanged $B_{12}$ reappears in plasma in the free state and may be excreted into the urine.

Whether the delay in transport of $B_{12}$ across the ileal cell is due to degradation of intrinsic factor, mitochondrial localisation, ${ }^{5}$ or to delay in TC II synthesis remains to be studied.

\section{References}

${ }^{1}$ Hall, C A, fournal of Clinical Investigation, 1975, 56, 1125.

${ }^{2}$ England, J M, et al, British fournal of Haematology, 1973, 25, 737.

3 Begley, J A, and Hall, C A, Blood, 1975, 45, 281.

${ }^{4} \mathrm{Hom}, \mathrm{B}$ L, Scandinavian fournal of Haematology, 1967, 4, 321.

${ }^{5}$ Peters, T J, and Hoffbrand, A V, British fournal of Haematology, 1970, 19, 369.

(Accepted 28 March 1978)

\section{SHORT REPORTS}

\section{Bone marrow aspiration for chromosome analysis in newborn}

Shaw ${ }^{1}$ and Smithies and Valman ${ }^{2}$ reported two infants with Down's syndrome complicated by duodenal obstruction where the diagnosis was confirmed by chromosome analysis of bone marrow cultures within eight and five hours, respectively. This prompted us to evaluate this technique in the management of selected infants born with suspected chromosome abnormalities.

\section{Patients, methods, and results}

During the period October 1974 to June 1977 chromosome analysis was performed on bone marrow aspirates from 14 newborn infants with congenital malformations (table). There were no complications from this procedure. The aspirate was unsatisfactory in case 6 as a result of haemodilu- tion. The group constituted $10 \%$ of the 139 neonatal cytogenetic referrals from an estimated population of 15158 live births during the same period.

Bone marrow (one drop to $0.2 \mathrm{ml}$ ) was obtained from the iliac crest using a Gimsome medullary needle. It was placed immediately in a heparinised tube containing tissue culture medium (Wellcome 199 ) plus $10 \%$ calf serum (Tissue Culture Services). In the laboratory it was diluted into four tubes containing $4 \mu \mathrm{g} / \mathrm{ml}$ demecolcine. One of these was harvested after $10 \mathrm{~min}$ incubation followed by suspension in fresh $0.075 \mathrm{M} \mathrm{KCl}$ for $18 \mathrm{~min}$ with one fixation using 3:1 methanol-glacial acetic acid. Air-dried chromosome preparations, temporarily stained with a drop of lactopropionic orcein, were selected, and a photographic print provided by a Polaroid camera attachment facilitated karyotypic confirmation of the diagnosis. If necessary, the remaining cultures were harvested sequentially until a result was available, usually $1-4$ hours from receiving the specimen.

Eight infants $(57 \%)$ tested by bone marrow analysis had a chromosome abnormality compared with $20(16 \%)$ of the remaining 125 infants where an analysis was performed on peripheral blood. The difference reflects the strong suspicion of chromosome abnormality in the former group. In no case was the result ambiguous, although the reciprocal translocation in case 7 was conclusively resolved only by banding.

Referrals for urgent bone marrow cytogenetic diagnosis

\begin{tabular}{|c|c|c|c|c|c|}
\hline $\begin{array}{l}\text { Case } \\
\text { No }\end{array}$ & $\begin{array}{c}\text { Age at } \\
\text { marrow } \\
\text { aspiration } \\
\text { (hours) }\end{array}$ & $\begin{array}{l}\text { Satisfactory } \\
\text { marrow } \\
\text { specimen }\end{array}$ & $\begin{array}{l}\text { Marrow } \\
\text { confirms }(\mathrm{C}) \\
\text { or } \\
\text { refutes }(\mathbf{R}) \\
\text { suspected } \\
\text { chromosome } \\
\text { abnormality }\end{array}$ & Karyotype & Clinical problem requiring urgent chromosome analysis \\
\hline $\begin{array}{l}1 \\
2 \\
3 \\
4 \\
5 \\
6 \\
7\end{array}$ & $\begin{array}{l}13 \\
14 \text { days } \\
30 \\
2 \\
6 \\
16 \\
19\end{array}$ & $\begin{array}{l}\text { Yes } \\
\text { Yes } \\
\text { Yes } \\
\text { Yes } \\
\text { Yes } \\
\text { No } \\
\text { Yes }\end{array}$ & $\begin{array}{l}\mathbf{C} \\
\mathbf{R} \\
\mathbf{C} \\
\mathbf{R} \\
\mathbf{C} \\
\mathbf{C}\end{array}$ & \multirow{4}{*}{ 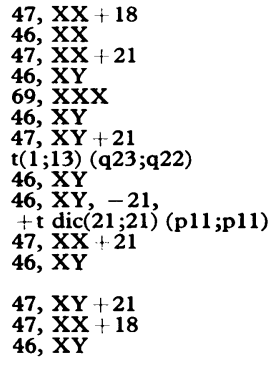 } & $\begin{array}{l}\text { Prominent occiput, overlapping fingers, short hallux, ptosis; ?trisomy } 18^{*} \\
\text { Gastroschisis; ?chromosome abnormality* } \\
\text { Down's syndrome with duodenal atresia* } \\
\text { Potter's syndrome; ?chromosome abnormality* } \\
\text { Flat nose, low set ears, syndactyly, large head, severe rhesus incompatibility* } \\
\text { Birth asphyxia, seizures, low set ears, epicanthic folds } \\
\text { Down's syndrome with ambiguous genitalia }\end{array}$ \\
\hline $\begin{array}{l}8 \\
9\end{array}$ & 2 days & $\begin{array}{l}\text { Yes } \\
\text { Yes }\end{array}$ & $\begin{array}{l}\mathbf{R} \\
\mathbf{C}\end{array}$ & & $\begin{array}{l}\text { Asphyxia, odd facies, low set ears, single palmar crease; ?Down's syndrome } \\
\text { Down's syndrome }\end{array}$ \\
\hline 10 & $\mathbf{6}$ & $\begin{array}{l}\text { Yes } \\
\text { Yes }\end{array}$ & $\begin{array}{l}\mathbf{C} \\
\mathbf{R}\end{array}$ & & $\begin{array}{l}\text { Down's syndrome } \\
\text { Asphyxia, laryngeal web, imperforate anus, ambiguous genitalia, abnormal } \\
\text { hands*t }\end{array}$ \\
\hline $\begin{array}{l}12 \\
13 \\
14\end{array}$ & $\begin{array}{r}24 \\
24 \\
9\end{array}$ & $\begin{array}{l}\text { Yes } \\
\text { Yes } \\
\text { Yes }\end{array}$ & $\begin{array}{l}\mathbf{C} \\
\mathbf{C} \\
\mathbf{R}\end{array}$ & & $\begin{array}{l}\text { Down's syndrome } \\
\text { Multiple abnormalities; ?trisomy } 18^{*} \\
\text { Cleft palate, abnormal hands, congenital heart disease; ?trisomy } 13^{*}\end{array}$ \\
\hline
\end{tabular}

